\title{
Analytical Studies of Full-scale Steel T-stub Connections Using Delicate 3D Finite Element Methods
}

\author{
Jong Wan HU, ${ }^{1)}$ Dong Keon $\mathrm{KIM}^{2)}$ Roberto T. $\mathrm{LEON}^{3)}$ and Eunsoo $\mathrm{CHOI}^{4)}$ \\ 1) Associate Research Fellow, Office of National R\&D Investment Strategy and Analysis, Korea Institute of S\&T Evaluation and \\ Planning (KISTEP), Seoul, 137-130 Korea. Email: jongp24@kistep.re.kr 2 2) Research Assistant Professor, Sustainable \\ Building Research Center, Hanyang University, Ansan, 426-791 Korea. Email: dkkzone@hanyang.ac.kr 3) Professor, \\ School of Civil and Environmental Engineering, Georgia Institute of Technology, Atlanta, GA, 30332 USA. Email: \\ rl58@ce.gatech.edu $\quad$ 4) Associate Professor, Department of Civil Engineering, Hongik University, Seoul, $121-791$ Korea. \\ E-mail: eunsoochoi@hongik.ac.kr
}

(Received on November 1, 2010; accepted on December 22, 2010)

\begin{abstract}
This study presents the development of refined three dimensional (3D) finite element (FE) models with the ability to reliably simulate the mechanical behavior of full-scale bolted T-stub connections. FE models incorporated material nonlinearity, geometric nonlinear behavior, several contact interactions between faying surfaces, and prescribed displacements for generating initial bolt pretension. These FE models were used to compare experimental test results, which verify that advanced FE modeling methods make a notable contribution to reproducing the overall behavior of connections and components accurately, including the moment-rotation curves. In addition, the FE models provide some useful information which is difficult to obtain during physical testing, i.e., the distribution of stress and strain, friction forces between shear faying surfaces, and bolt reaction forces. The validated FE models are also used for additional parametric studies so as to comprehensively understand their response mechanisms. Moreover, the observation of FE analysis results supports the statement that connection models presented herein were designed to reach the yielding of connection components when the structural beam produces its full plastic moment at the plastic hinge.
\end{abstract}

KEY WORDS: finite element (FE) analysis; T-stub connection; slip; bolt pretension; prying mechanism.

\section{Introduction}

In the past two decades, the incorporation of bolted connections into steel moment frame design has attracted attention since fully welded moment connections conventionally utilized in the practical construction field had inherent drawbacks. ${ }^{1-6)}$ The unexpected failure often occurring at the welded moment connections is related to the connection geometry, which accelerates large strain demand in critical sections. These strain demands will cause the fracture of the base metal around the weld access hole. It results in low rotational ductility and poor behavioral performance under cyclic loads. ${ }^{3,4)}$ Therefore, other connection types should be introduced to moment frame design with a view to remove the brittle failure of corresponding welded connections.

Bolted steel connections are one alternative on the ground that they can avoid the strain concentration and localization problems. ${ }^{7-10)}$ It is the cause that these bolted connections are generally fabricated by the assemblage of various connection components (e.g., plates, connectors, and bolts). Accordingly, the bolted connection system throughout the moment frame provides a high level of redundancy and the intermediate level of stiffness in comparison with fully welded connections. ${ }^{10-12)}$

The global behavior of bolted connections commonly represented by the moment-rotation curve becomes complex because the various response mechanisms of individual components interact with each other. These response mechanisms are associated with the large variety of connection configurations, geometrical discontinuities, nonlinearconstitutive relationships for base materials, frictional forces that lead to slip, and bolt pretensions that lead to prying action. $^{13,14)}$ Though the large number of these variables should be taken into consideration, this research attempts to fully understand the response mechanism for the complete behavior of T-stub connections through analytical studies provided by finite element (FE) methods.

The FE models are adequate to simulate complex and nonlinear behavior with considerable accuracy because they require the sophisticated preparation process. ${ }^{15)}$ Nevertheless, in spite of this profit, the previous FE studies conducted on T-stub connections have been limited to only local T-stub components $^{7,8,14-16)}$ instead of entire beam-to-column subassemblages. For component tests, the axial loads assumed to be beam-flange forces in the actual connection are only applied to the T-stub components. A large number of parameters were investigated economically and rapidly through the component tests. However, they produce a restricted prediction to estimate strength, ductility, and stiffness of fullscale connections, since both localized bending moments 
and shear forces presented in the actual condition are missing in these component tests. Therefore, this study intends to develop full-scale FE connection models in order to generate complete-nonlinear moment-rotation curves, which are involved with modern structural analysis programs and upto-date computational equipments. After refined FE analyses, parametric investigations on T-stub components and their bolts are presented to demonstrate how the geometric variations in those components can affect the behavior and strength capacity of individual connection models.

\section{Experimental Program}

An experimental program was performed as a part of the SAC Subtask 7.03 research project at Georgia Tech. Smallidge ${ }^{17)}$ and Schrauben ${ }^{18)}$ individually tested eight fullscale connection specimens with T-stub components. The specimens were built with beams and columns connected by T-stubs, according to the standard AISC-LRFD manual. ${ }^{19)}$

A typical specimen and its test set-up are illustrated in Fig. 1. The details of all specimens such as section and

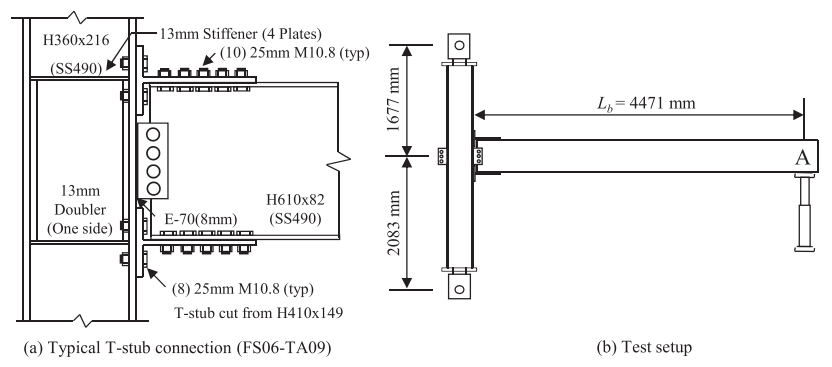

Fig. 1. Typical T-stub connection and its test setup. material properties are summarized in Table 1, along with the ultimate moments obtained in the experiment. The typical test configuration was made up of an H360×216 column with pinned end supports, a $4.5 \mathrm{~m}$ length beam which varied from an $\mathrm{H} 530 \times 66$ to $\mathrm{H} 690 \times 125$ section, and three connecting members which are two T-stubs and a shear tab. The panel zones of first two test models (i.e., FS03 and FS04 model) were not reinforced with stiffeners or doubler plates. On the other hand, unlike the previous two tests, the panel zones of FS05 through FS08 model were reinforced with four $13 \mathrm{~mm}$ thick stiffeners and a $13 \mathrm{~mm}$ thick doubler plate on one side of the column web (see Fig. 1(a)). Except for the beam in the FS08 model, which was SS330 (A36) steel, all connection members were fabricated from SS490 (A572 Gr.50) carbon steel. The steel strengths were obtained from the mill certificates. The cyclic displacement load history was applied to the tip of the steel beam (see A in Fig. 1(b)).

The specimen identifications (IDs) consist of the test number and the T-stub classification. For instance, the FS06-TA09 model consists of "FS" which represents fullscale, "06" which represents the test number, and "TA09" which indicates the T-stub classification. The test series of T-stub components, which are TA, TB, TC, and TD listed in Table 1, were classified by the T-stub flange thickness $\left(t_{f}\right)$ ranged from $14 \mathrm{~mm}$ to $32 \mathrm{~mm}$. As listed in the table, $22 \mathrm{~mm}$ and $25 \mathrm{~mm}$ diameter tension bolts were used in a pair of test series (e.g., TA01 vs. TA09), along with the tensile capacity of steel bolts based on the M10.8 (ASTM A490) highstrength bolt material. The dimensions and instrumentation scheme of T-stub components are given in Figs. 2 and 3, respectively. ${ }^{17,18)}$ The T-stubs were cut from standard wide

Table 1. Details of full scale T-stub connection models.

\begin{tabular}{|c|c|c|c|c|c|c|c|c|c|c|c|c|c|c|}
\hline \multirow{2}{*}{$\begin{array}{l}\text { Model } \\
\text { ID }\end{array}$} & \multicolumn{4}{|c|}{ T-Stub } & \multicolumn{3}{|c|}{ Beam } & \multicolumn{3}{|c|}{ Column } & \multicolumn{2}{|c|}{ Bolt } & \multirow{2}{*}{$\begin{array}{c}\begin{array}{c}\text { Shear } \\
\text { Tab }\end{array} \\
\text { Size*** }\end{array}$} & \multirow{2}{*}{$\begin{array}{c}\begin{array}{c}\text { Peak } \\
\text { Moment }\end{array} \\
\begin{array}{c}\text { Exp. } \\
\text { Model }\end{array}\end{array}$} \\
\hline & $\begin{array}{l}\text { Model } \\
\text { ID }\end{array}$ & Size* & $\begin{array}{l}\text { Yield } \\
\text { Stress** }\end{array}$ & $\begin{array}{l}\text { Ultimate } \\
\text { Stress*** }\end{array}$ & Size* & $\begin{array}{l}\text { Yield } \\
\text { Stress** }\end{array}$ & $\begin{array}{l}\text { Ultimate } \\
\text { Stress** }\end{array}$ & Size* & $\begin{array}{c}\text { Yield } \\
\text { Stress** }\end{array}$ & $\begin{array}{l}\text { Ultimate } \\
\text { Stress** }\end{array}$ & $\underset{* * *}{\text { Diameter }}$ & $\begin{array}{c}\text { Tensile } \\
\text { Capacity**** }\end{array}$ & & \\
\hline FS03 & TD04 & $\begin{array}{l}\mathrm{H} 410 \\
\times 67\end{array}$ & $\begin{array}{c}396(\mathrm{~F}) \\
427(\mathrm{~W})\end{array}$ & $\begin{array}{l}557(\mathrm{~F}) \\
569(\mathrm{~W})\end{array}$ & $\begin{array}{l}\mathrm{H} 530 \\
\times 66\end{array}$ & 400 & 489 & $\begin{array}{l}\mathrm{H} 360 \\
\times 216\end{array}$ & 386 & 516 & 22 & $\begin{array}{l}334(\mathrm{~T}) \\
336(\mathrm{~S})\end{array}$ & $\begin{array}{c}10 \times 127 \\
\times 229\end{array}$ & $650 \mathrm{kN}-\mathrm{m}$ \\
\hline FS04 & TD08 & $\begin{array}{l}\mathrm{H} 410 \\
\times 67\end{array}$ & $\begin{array}{c}396(\mathrm{~F}) \\
427(\mathrm{~W})\end{array}$ & $\begin{array}{c}557(\mathrm{~F}) \\
569(\mathrm{~W})\end{array}$ & $\begin{array}{l}\text { H530 } \\
\times 66\end{array}$ & 400 & 489 & $\begin{array}{l}\mathrm{H} 360 \\
\times 216\end{array}$ & 386 & 516 & 25 & $\begin{array}{l}438(\mathrm{~T}) \\
435(\mathrm{~S})\end{array}$ & $\begin{array}{c}10 \times 127 \\
\times 229\end{array}$ & $681 \mathrm{kN}-\mathrm{m}$ \\
\hline FS05 & TA01 & $\begin{array}{l}\mathrm{H} 410 \\
\times 149\end{array}$ & $\begin{array}{l}318(\mathrm{~F}) \\
352(\mathrm{~W})\end{array}$ & $\begin{array}{c}460(\mathrm{~F}) \\
469(\mathrm{~W})\end{array}$ & $\begin{array}{c}\mathrm{H} 610 \\
\times 82\end{array}$ & 420 & 523 & $\begin{array}{l}\mathrm{H} 360 \\
\times 216\end{array}$ & 386 & 516 & 22 & $\begin{array}{l}334(\mathrm{~T}) \\
336(\mathrm{~S})\end{array}$ & $\begin{array}{c}10 \times 127 \\
\times 305\end{array}$ & $1010 \mathrm{kN}-\mathrm{m}$ \\
\hline FS06 & TA09 & $\begin{array}{l}\mathrm{H} 410 \\
\times 149\end{array}$ & $\begin{array}{l}318(\mathrm{~F}) \\
352(\mathrm{~W})\end{array}$ & $\begin{array}{c}460(\mathrm{~F}) \\
469(\mathrm{~W})\end{array}$ & $\begin{array}{l}\mathrm{H} 610 \\
\times 82\end{array}$ & 420 & 523 & $\begin{array}{l}\mathrm{H} 360 \\
\times 216\end{array}$ & 386 & 516 & 25 & $\begin{array}{l}438(\mathrm{~T}) \\
435(\mathrm{~S})\end{array}$ & $\begin{array}{c}10 \times 127 \\
\times 305\end{array}$ & $1010 \mathrm{kN}-\mathrm{m}$ \\
\hline FS07 & TB01 & $\begin{array}{l}\mathrm{H} 530 \\
\times 138\end{array}$ & $\begin{array}{l}362(\mathrm{~F}) \\
378(\mathrm{~W})\end{array}$ & $\begin{array}{l}498(\mathrm{~F}) \\
501(\mathrm{~W})\end{array}$ & $\begin{array}{l}\mathrm{H} 610 \\
\times 82\end{array}$ & 420 & 523 & $\begin{array}{l}\mathrm{H} 360 \\
\times 216\end{array}$ & 386 & 516 & 22 & $\begin{array}{l}334(\mathrm{~T}) \\
336(\mathrm{~S})\end{array}$ & $\begin{array}{c}10 \times 127 \\
\times 305\end{array}$ & $1060 \mathrm{kN}-\mathrm{m}$ \\
\hline FS08 & TB05 & $\begin{array}{l}\mathrm{H} 530 \\
\times 138\end{array}$ & $\begin{array}{l}362(\mathrm{~F}) \\
378(\mathrm{~W})\end{array}$ & $\begin{array}{l}498(\mathrm{~F}) \\
501(\mathrm{~W})\end{array}$ & $\begin{array}{l}\mathrm{H} 610 \\
\times 82\end{array}$ & 372 & 487 & $\begin{array}{l}\mathrm{H} 360 \\
\times 216\end{array}$ & 386 & 516 & 25 & $\begin{array}{l}438(\mathrm{~T}) \\
435(\mathrm{~S})\end{array}$ & $\begin{array}{c}10 \times 127 \\
\times 305\end{array}$ & $985 \mathrm{kN}-\mathrm{m}$ \\
\hline FS09 & TC01 & $\begin{array}{l}\mathrm{H} 840 \\
\times 251\end{array}$ & $\begin{array}{c}390(\mathrm{~F}) \\
415(\mathrm{~W})\end{array}$ & $\begin{array}{l}523(\mathrm{~F}) \\
530(\mathrm{~W})\end{array}$ & $\begin{array}{l}\mathrm{H} 690 \\
\times 125\end{array}$ & 415 & 510 & $\begin{array}{l}\mathrm{H} 360 \\
\times 216\end{array}$ & 386 & 516 & 22 & $\begin{array}{l}334(\mathrm{~T}) \\
336(\mathrm{~S})\end{array}$ & $\begin{array}{c}10 \times 127 \\
\times 381\end{array}$ & $1890 \mathrm{kN}-\mathrm{m}$ \\
\hline FS10 & ТC09 & $\begin{array}{l}\mathrm{H} 840 \\
\times 251\end{array}$ & $\begin{array}{l}390(\mathrm{~F}) \\
415(\mathrm{~W})\end{array}$ & $\begin{array}{l}523(\mathrm{~F}) \\
530(\mathrm{~W})\end{array}$ & $\begin{array}{l}\mathrm{H} 690 \\
\times 125\end{array}$ & 415 & 510 & $\begin{array}{l}\mathrm{H} 360 \\
\times 216\end{array}$ & 386 & 516 & 25 & $\begin{array}{l}438(\mathrm{~T}) \\
435(\mathrm{~S})\end{array}$ & $\begin{array}{c}10 \times 127 \\
\times 381\end{array}$ & $1990 \mathrm{kN}-\mathrm{m}$ \\
\hline
\end{tabular}

*: Metric Size $\quad * *: \mathrm{MPa}$ (Coupon Tests) $\quad * * *: \mathrm{mm} \quad * * * *: \mathrm{kN}$

H530×66 Beam: $d=525 \mathrm{~mm}, t_{w}=8.9 \mathrm{~mm}, b_{f}=165 \mathrm{~mm}, t_{f}=11.4 \mathrm{~mm}$; H610×82 Beam: $d=599 \mathrm{~mm}, t_{w}=10 \mathrm{~mm}, b_{f}=178 \mathrm{~mm}, t_{f}=12.8 \mathrm{~mm}$;

H690 $\times 125$ Beam: $d=678 \mathrm{~mm}, t_{w}=11.7 \mathrm{~mm}, b_{f}=253 \mathrm{~mm}, t_{f}=16.3 \mathrm{~mm} ; \mathrm{H} 360 \times 216$ Column: $\mathrm{d}=375 \mathrm{~mm}, \mathrm{tw}=17.3 \mathrm{~mm}, b_{f}=394 \mathrm{~mm}, t_{f}=27.7 \mathrm{~mm}$;

F: Flange W: Web T: Tension Bolt S: Shear Bolt $d$ : Beam Depth $t_{w}$ : Web Thickness $b_{f}$ : Flange Width $t_{f}$ : Flange Thickness 

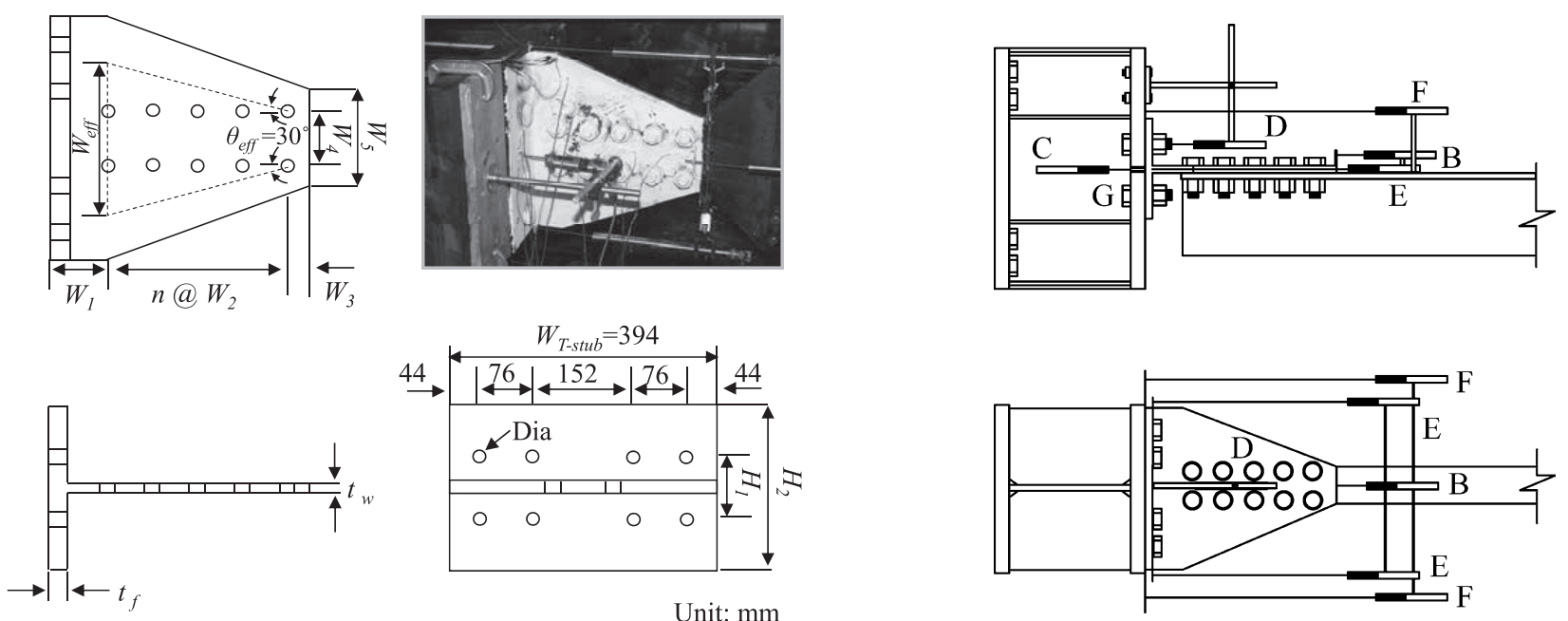

Fig. 2. Details of T-stub components. ${ }^{17,18)}$

Fig. 3. Instrumentation scheme for experimental tests.

Table 2. Geometric size of T-stub components

\begin{tabular}{|c|c|c|c|c|c|c|c|c|c|c|c|}
\hline Model & $W_{l}$ & $W_{2}(n)$ & $W_{3}$ & $W_{4}$ & $W_{5}$ & $t_{f}$ & $t_{w}$ & $H_{l}$ & $H_{2}$ & Dia. & Bolt Size \\
\hline TA01 & 84 & $67(4)$ & 33 & 89 & 152 & 25 & 14 & 102 & 264 & 24 & $\begin{array}{l}22 \times 114 \mathrm{~mm}(\mathrm{~T})^{*} \\
22 \times 76 \mathrm{~mm}(\mathrm{~S}) * *\end{array}$ \\
\hline TA09 & 89 & $76(3)$ & 38 & 89 & 152 & 25 & 14 & 102 & 264 & 27 & $\begin{array}{c}25 \times 114 \mathrm{~mm}(\mathrm{~T}) \\
25 \times 89 \mathrm{~mm}(\mathrm{~S})\end{array}$ \\
\hline TB01 & 84 & $67(4)$ & 33 & 102 & 178 & 24 & 14 & 102 & 213 & 24 & $\begin{array}{c}22 \times 114 \mathrm{~mm}(\mathrm{~T}) \\
22 \times 89 \mathrm{~mm}(\mathrm{~S})\end{array}$ \\
\hline TB05 & 89 & $76(4)$ & 38 & 102 & 178 & 24 & 14 & 102 & 213 & 27 & $\begin{array}{c}25 \times 114 \mathrm{~mm}(\mathrm{~T}) \\
25 \times 89 \mathrm{~mm}(\mathrm{~S})\end{array}$ \\
\hline TC01 & 90 & $67(5)$ & 33 & 127 & 241 & 32 & 17 & 127 & 292 & 24 & $\begin{array}{c}22 \times 127 \mathrm{~mm}(\mathrm{~T}) \\
22 \times 89 \mathrm{~mm}(\mathrm{~S})\end{array}$ \\
\hline ТC09 & 95 & $76(5)$ & 38 & 127 & 241 & 32 & 17 & 127 & 292 & 27 & $\begin{array}{l}25 \times 127 \mathrm{~mm}(\mathrm{~T}) \\
25 \times 102 \mathrm{~mm}(\mathrm{~S})\end{array}$ \\
\hline TD04 & 84 & $67(3)$ & 33 & 89 & 152 & 14 & 10 & 102 & 178 & 24 & $\begin{array}{l}22 \times 95 \mathrm{~mm}(\mathrm{~T}) \\
22 \times 76 \mathrm{~mm}(\mathrm{~S})\end{array}$ \\
\hline TD08 & 89 & $76(3)$ & 38 & 89 & 152 & 14 & 10 & 102 & 178 & 27 & $\begin{array}{l}25 \times 95 \mathrm{~mm}(\mathrm{~T}) \\
25 \times 83 \mathrm{~mm}(\mathrm{~S})\end{array}$ \\
\hline
\end{tabular}

$*(\mathrm{~T})=$ Tension bolts, $* *(\mathrm{~S})=$ Shear bolts, SS490 (A572-Gr.50) steel, Grade for all used bolts $=$ M10.9 (ASTM A490)

flange sections so as to install more than 8 shear bolts on the tapered T-stem. As summarized in Table 2, the size, grade, number, gauge, and spacing of the bolts were varied to investigate the effect of prying action on the tension flange and slip on the T-stem. The oversized bolt holes including the clearance to the diameter of the bolt were applied to all specimens for construction.

The experimental tests were extensively instrumented with linear variable displacement transducers (LVDTs) which were mounted on the top and bottom of the beam flanges (see Fig. 3). In addition to connection rotations, each pair of LVDTs measured individual T-stub displacements which result in the different components of the overall $\mathrm{T}$ stub deformation. Thus, LVDTs B measured the slip, LVDTs $\mathrm{C}$ measured the uplift of the T-stub flange from the face of the column flange, LVDTs D measured the elevation of the T-stub flange at the bolt line, LVDTs E measured the elongation of the T-stem, and LVDTs F monitored the overall Tstub deformation.

\section{Theoretical Background}

\subsection{Full Connection Behavior}

The total applied force measured at the tip of the beam $(T)$ should be changed into the bending moment by applying a first order approximation (see Eq. (1)) in order to obtain the characteristics of connections from the experimental results. The resisting response mechanism for connection behavior is illustrated in Fig. 4. The reaction responses transformed from external forces are computed as follows:

$$
M_{r}=M_{x}+V x=T L_{b}
$$

where $V$ is the shear force carried by the beam; $M_{r}$ is the internal resistant moment; $M_{x}$ is the moment of the framing beam; $x$ is the distance from the column surface to the position of the moment; and $L_{b}$ is the length of the beam. The strength for connection design is determined by the full plastic moment of the beam at the plastic hinge defined as:

$$
M_{p}=Z_{b} F_{y}
$$

where $Z_{b}$ is the plastic section modulus; and $F_{y}$ is the plastic 
yield stress of the base material. The internal reactions in the component members correspond to the external forces on account of the static equilibrium. They have the following relationship as shown in Fig. 4:

$$
M_{r}=\Sigma B_{n 1} H_{B 1}+\Sigma B_{n 2} H_{B 2}-Q_{1} H_{Q 1}-Q_{2} H_{Q 2}
$$

where $\Sigma B_{n 1}$ and $\Sigma B_{n 2}$ indicate the summation of bolt reaction forces in tension; $Q_{1}$ and $Q_{2}$ stand for the prying forces acting on the tip of the T-stub flange; $H_{B 1}, H_{B 2}, H_{Q 1}, H_{Q 2}$, and $H_{Q 2}$ are the equivalent heights at each position. The prying forces arise from the local bending action associated with the initial bolt pretension $\left(B_{\text {pre }}\right)$ in the T-stub flange. The rotations are derived from linear displacements that are measured at the tip of the beam. The total rotation of the connection is calculated by:

$$
\varphi_{\text {total }}=\arctan \left(\Delta_{\text {beam }} / L_{b}\right)
$$

where $\Delta_{\text {beam }}$ denotes the beam tip displacement.

\subsection{Component Strength Models}

The bending moment $(M)$ transformed from the total applied force at the tip of the beam is transmitted into the connection as the converted axial forces $(P)$. They are computed by dividing the external moment force into the depth of the beam $(d)$ as follows:

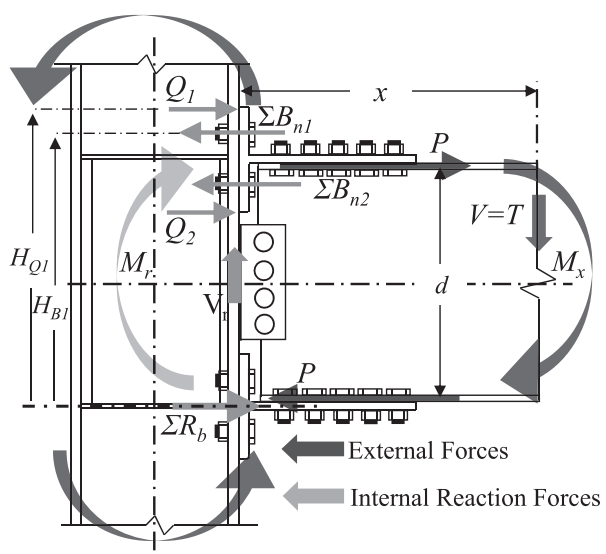

Fig. 4. Internal and external force mechanism acting on full scale $\mathrm{T}$-stub connections.

$$
P=\frac{M}{d}
$$

The internal reactions in the T-stub component act against these axial forces to satisfy the fundamental static equilibrium. They show the following relationship as illustrated in Fig. 4:

$$
P=\Sigma B_{n 1}+\Sigma B_{n 2}-Q_{1}-Q_{2}
$$

Thus, the T-stub components mostly deform by the converted axial forces transferred from the beam flange. The major response mechanisms that create the overall deformation of T-stub components are made up of the flange deformation, tension bolt elongation, T-stem deformation, and relative slip. ${ }^{7,8,20)}$ These response mechanisms are derived independently from the component test results and correlate well with simplified strength models.

The mechanisms from tension bolts under stretching and a T-stub flange under bending should be treated together to estimate the strength capacity of the T-stub flange because their behaviors are inherently coupled during the force transfer. ${ }^{720}$ The established prying model accepted in the design guideline ${ }^{19)}$ has been used to assess the ultimate strength capacity of the T-stub flange $\left(P_{n \text { flange }}\right)$. This prying model was based on one of most widely used models proposed by Kulak et al. ${ }^{21)}$

Three possible failure modes occurring at the T-stub flange and tension bolts are equationally expressed as Eqs. (7) to (9) and illustrated in Fig. 5. These failure modes are relevant to the formation of a plastic mechanism on the Tstub flange (Eq. (7) and Fig. 5(a)), the plastic yielding of the T-stub flange combined with bolt prying (Eq. (8) and Fig. $5(\mathrm{~b})$ ), and the fracture of tension bolts without prying forces (Eq. (9) and Fig. 5(c)) as follows:

$$
\begin{aligned}
& P_{n, \text { flange }}=\frac{(1+\delta) W_{T-\text { stub }} F_{y} t_{f}^{2}}{2 b^{\prime}} \\
& P_{n, \text { flange }}=\frac{\sum B_{n, \text { tension }} a^{\prime}}{a^{\prime}+b^{\prime}}+\frac{W_{T-\text { stub }} F_{y} t_{f}^{2}}{2 b^{\prime}} \\
& P_{n, \text { flange }}=\sum B_{n, \text { tension }}
\end{aligned}
$$

where $W_{\text {T-stub }}$ is the width of the T-stub flange (see Fig. 2);

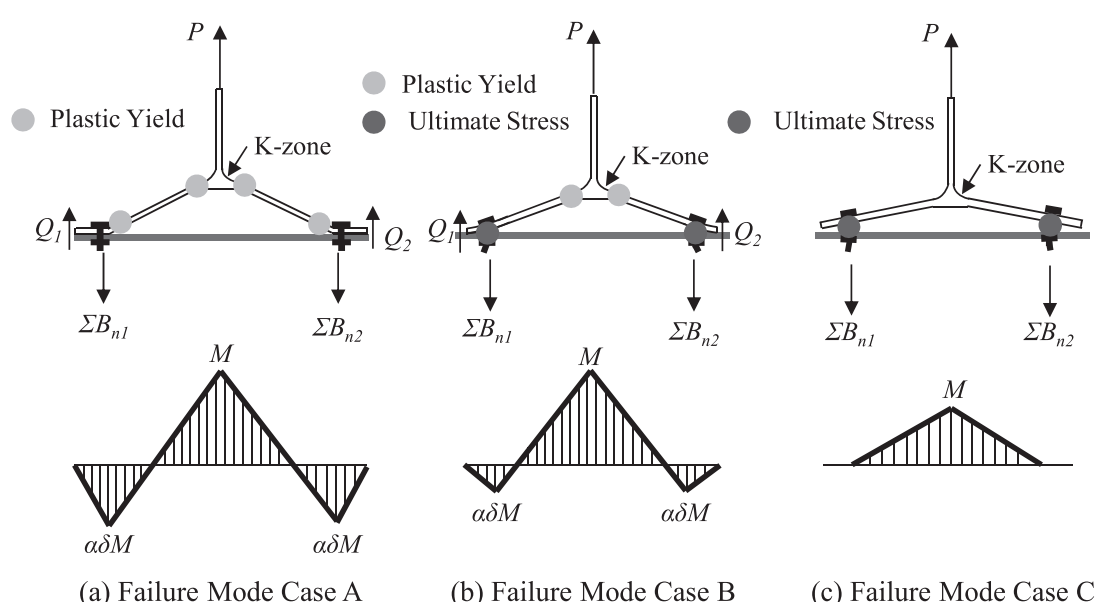

Fig. 5. Three possible failure modes and their moment distribution due to bolt/flange prying action. 
$a^{\prime}$ and $b^{\prime}$ substituted for $a$ and $b$ (see Fig. 6) indicate the geometric parameters resulting from the precondition that most of bolt reaction forces are assumed to be transferred into the inside edge of the bolt shank rather than the centerline of the bolt shank; ${ }^{21,22)} \Sigma B_{n, \text { tension }}$ is the tensile capacity of tension bolts used for design (see Table 1 ); $\delta$ denotes the ratio of the net section area to the gross section area and is written as:

$$
\delta=1-\frac{n_{t b} d_{h}}{W_{T-s t u b}}
$$

where $d_{h}$ is the diameter of the bolt hole; and $n_{t b}$ is the number of tension bolts per each row. The geometric notations for the prying model are shown in Fig. 6 .

The parameter $\alpha$ indicates the index of the level of the prying action present. ${ }^{21)}$ It is defined as the ratio of the moment at the inside bolt edge to the moment at the face of the T-stem (see Fig. 5) and is expressed as follows:

$$
\alpha=\left(\frac{1}{\delta}\right)\left(\frac{2 n_{t b} P b^{\prime}}{W_{T-s t u b} t_{f}^{2} F_{y}}-1\right)
$$

When the value of $\alpha$ is equal to 1.0, Eq. (7) is derived from Eq. (11). When $\alpha \geq 1.0$, T-stub flanges are more susceptible to the plastic hinge and prying forces are maximized. Accordingly, the T-stub flange is considered to be a fixedfixed beam in this case (Failure Mode Case A shown in Fig. 5(a)). When $0<\alpha<1.0$, the combination of flange yielding and bolt fractures due to bolt prying may occur at the T-stub flange (Failure Mode Case B shown in Fig. 5(b)). Finally, if $\alpha \leq 0$, then the T-stub flange completely separates from the column surface, prying forces become zero, and then tension bolts are theoretically subjected to pure stretching (Failure Mode Case C shown in Fig. 5(c)). However, stress concentration developed as a consequence of the local bending moment occurs underneath the one-sided bolt head in practice. The prying forces are minimized by augmenting the thickness of the T-stub flange or by decreasing the geometric ratio of $H_{1}$ to $H_{2}{ }^{21,22)}$ Due to a static equilibrium illustrated in Eq. (6), these prying forces make a contribution to increasing the bolt reaction forces $\left(B_{n}\right)$ and effectively reducing the applied axial loads $(P) .^{21)}$

The strength model for the T-stem is evaluated with a bilinear representation based on the effective net section strength. As shown in Fig. 2, an angle of 30 degree measured from the first row of shear bolts was used to define the effective width of the T-stub $\left(W_{\text {eff }}\right)$. This model was proposed by Whitemore. ${ }^{23)}$ The effective width of T-stem is

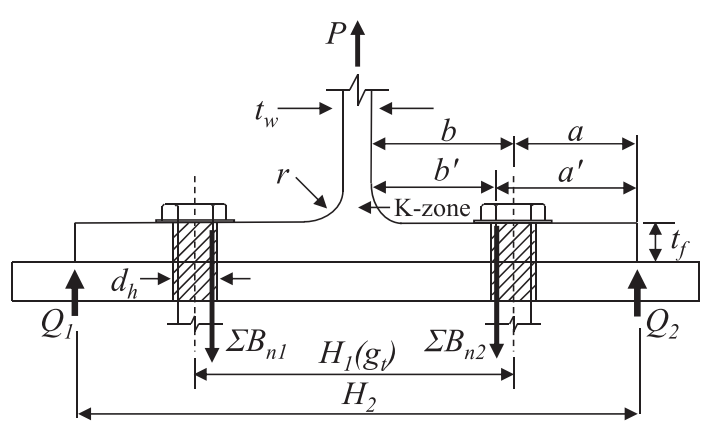

Fig. 6. Geometric notations for the prying action model of T-stub components. written as follows:

$$
W_{e f f}=s_{s b}\left(n_{s b}-2\right) \tan \left(\theta_{e f f}\right)+g_{s} \leq W_{T-s t u b}
$$

where $s_{s b}$ is the shear bolt spacing; $n_{s b}$ is the number of shear bolts; $\theta_{\text {eff }}$ is the effective angle of the tensile participation generally taken as 30 degree (see Fig. 2); and $g_{s}$ denotes the gage between two rows of the shear bolts. The smaller one between the Whitemore width and the actual width was used to compute the effective net section area of the T-stem $\left(A_{\text {stem }}\right)$. The shear bolt holes were excluded as a part of the net section area.

$$
A_{\text {stem }}=\left(W_{\text {eff }}-2 d_{h}\right) t_{w}
$$

where $t_{w}$ is the thickness of the T-stem. When the applied loads are distributed uniformly along the net section area, the yield and ultimate strength capacity of the T-stem are expressed, respectively, as follows:

$$
\begin{aligned}
& P_{y, \text { stem }}=F_{y} A_{\text {stem }} \\
& P_{u, \text { stem }}=F_{u} A_{\text {stem }}
\end{aligned}
$$

where $F_{u}$ is the ultimate stress of the base material.

The slip mechanism is characterized by the simple friction model given in the AISC-LRFD. ${ }^{19)}$ The slip-critical connections are designed with the slip resistance $\left(P_{\text {slip }}\right)$ which shall be equal or over the nominal slip resistance load $\left(P_{n, s l i p}\right)$ as follows:

$$
P_{n, s l i p}=1.13 u h_{s c} T_{b} n_{s} n_{s b}\left(1-\frac{P_{u}}{1.13 T_{b} n_{s b}}\right) \leq P_{s l i p} \ldots
$$

where $u$ is the mean slip coefficient for Class A, B, or C surfaces (for Class A surface, $u=0.33$ ); $h_{s c}$ is the coefficient for the standard bolt holes (i.e., $h_{s c}=1.0$ ); $T_{b}$ is the specified minimum fastener tension used in the AISC-LRFD (e.g., M10.8 bolt with $22 \mathrm{~mm}$ has $221 \mathrm{kN}$ ); and $n_{s}$ is the number of slip planes. Unpainted clean mill scale steel surfaces belonging to Class A were used for the mean slip coefficient. The applied ultimate axial force $\left(P_{u}\right)$ is computed by the product of the design reduction factor and the ultimate T-stub capacity (e.g., $P_{u}=\phi P_{n}: \phi=0.9$ for the plastic flange and $\phi=0.75$ for the bolt fracture).

Once the shear force transmitted from the applied axial force goes beyond the slip resistance, slippage begins to occur between two contact surfaces. The slip resistance results from the clamping force corresponding to the product of the bolt pretension and the friction coefficient (i.e., $\left.P_{\text {slip }}=B_{\text {pre }} \cdot u\right)$. The amount of slippage is equal to the clearance of the bolt hole to the diameter of the bolt shank $\left(\Delta_{c}\right)$, typically taken as $1.6 \mathrm{~mm}$. After slippage reaches the amount of the bolt clearance, the bolt shank begins to bear around the bolt hole, and then both stiffness and strength increase again.

\subsection{Failure Modes}

All T-stub connection models were designed to reach yielding on the connection components such as tension/ shear/web bolts, shear tab plates, and T-subs when the beam produced its full plastic moment at the plastic hinge. This design criterion fulfills the requirements for connection design given in both the AISC-LRFD manual ${ }^{19)}$ and the 
Table 3. Strength capacities of T-stub components.

\begin{tabular}{|c|c|c|c|c|c|c|c|}
\hline \multirow{2}{*}{ Model ID } & \multirow{2}{*}{$\begin{array}{c}\text { Beam Plastic Hinge } \\
P_{P}{ }^{*}\end{array}$} & \multicolumn{2}{|c|}{ Bolt/Flange Capacity } & \multicolumn{2}{|c|}{ T-Stem Capacity } & \multicolumn{2}{|c|}{ Experimental Results } \\
\hline & & $P_{n, f l a n g e} *(\alpha)$ & $\Sigma B_{\text {n.tension }} *$ & $P_{y . s t e m} *$ & $P_{\text {u.stem }} *$ & Peak Load $\left(P_{u . E x p} .\right)^{*}$ & Failure Mode** \\
\hline FS03-TD04 & 1189 & $1745(3.74)$ & 2667 & 1106 & 1476 & 1270 & Net Section \\
\hline FS04-TD08 & 1189 & $2300(5.27)$ & 3510 & 1214 & 1620 & 1316 & Net Section \\
\hline FS05-TA01 & 1551 & $2173(1.10)$ & 2667 & 1742 & 2317 & 1790 & Net Section \\
\hline FS06-TA09 & 1551 & $2788(1.71)$ & 3510 & 1504 & 2000 & 1738 & Net Section \\
\hline FS07-TB01 & 1551 & $2185(1.04)$ & 2667 & 1870 & 2473 & 1768 & S-Bolt \\
\hline FS08-TB05 & 1551 & $2800(1.63)$ & 3510 & 1836 & 2418 & 1643 & Net Section \\
\hline FS09-TC01 & 2428 & $2344(0.44)$ & 2667 & 2507 & 3202 & 2787 & T-Bolt \\
\hline FS10-TC09 & 2428 & $2930(0.83)$ & 3510 & 2461 & 3144 & 2934 & Net Section \\
\hline
\end{tabular}

*: Unit is $\mathrm{kN}$

**: Final Ultimate Failure

AISC Seismic Provisions. ${ }^{24)}$ In addition, connection components were designed with the intent to avoid the catastrophic losses of stiffness and strength due to brittle failures (e.g., bolt fracture). The design forces $\left(P_{p}\right)$ were obtained from the plastic moment of the beam as specified in the Seismic Provisions. ${ }^{24)}$ Accordingly, the ultimate strength capacity of T-stub connections $\left(P_{u}\right)$ shall be over the design force as follows:

$$
P_{p}=\frac{M_{p}}{d}<P_{u}=\frac{M_{u}}{d}
$$

Table 3 shows the strength capacities of individual T-stub components. Both peak loads $\left(P_{u, E X p}\right)$ and dominant failure modes, which were observed at experimental tests, ${ }^{17,18)}$ are also summarized in this table. The design strength $\left(P_{p}\right)$ is generally followed by T-stem yielding $\left(P_{y, s t e m}\right)$, and then immediately followed by the T-stem fracture at considerably large deformations. The adequacy of connection design can be verified by the fact that their ultimate capacities exceed the design strength as presented in the table (e.g., $\left.P_{u, E X p}>P_{p}\right)$. The relatively thin member thickness of the Tstem can lead to the major energy dissipation. This situation will provide a balanced failure which maximizes the deformation capacity of the T-stem. In an effort to achieve the balanced failure mode, most of the connection models were designed with the ultimate strength capacities for the T-stubs that finally failed with net section failures (see Eq. 18(a) and Table 3). The fractures have conventionally classified as the brittle failure but the level of the deformation associated with the net section fracture of the T-stem provides considerable ductility or energy dissipation compared to other brittle failures. It is due to membrane effects and the isotropic strain hardening of the base material. ${ }^{8)}$ The FS09-TC01 model as an exception was designed with the relatively thick thickness of the T-stem $\left(t_{w}=17 \mathrm{~mm}\right)$. Accordingly, the capacity of the T-stub flange is less than that of T-stem yielding (see Eq. 18(b) and Table 3). As a result, the tension bolt fracture combined with the plastic yielding of the T-stub flange was observed at this connection model. Bolt fractures are one of the failure modes that should be avoided because they may cause sudden strength degradation in the whole structure. The sequence of failure modes accompanied with the strength capacities of individual T-stub components can be written as follows:

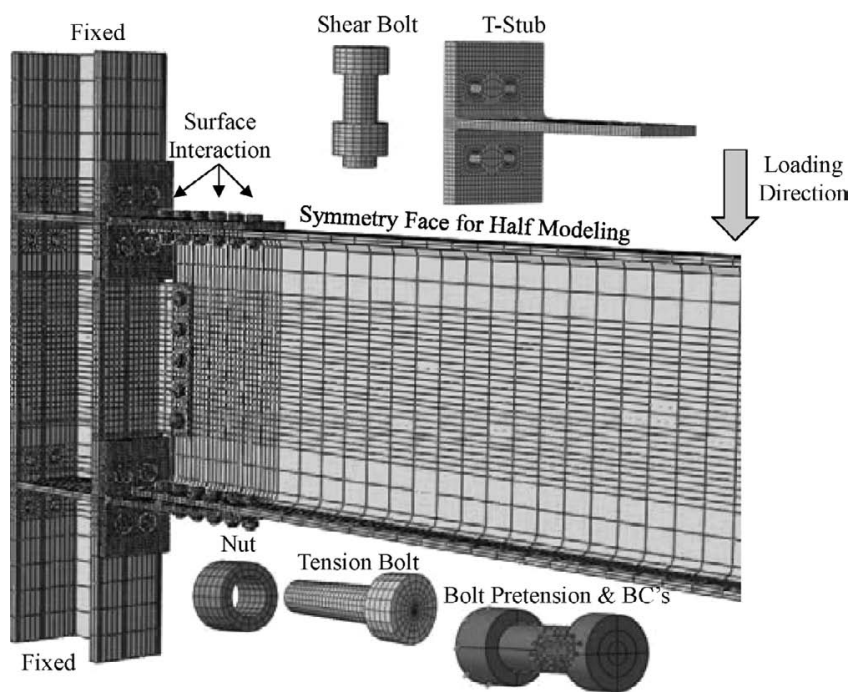

Fig. 7. 3D FE T-stub connection model and its independent parts.

$$
\begin{aligned}
& P_{y, \text { stem }} \leq P_{u, \text { Exp. }}<P_{u, \text { stem }} \leq P_{n, \text { flange }} \ldots \ldots \ldots . . . .(18(\mathrm{a})) \\
& P_{n, \text { flange }} \leq P_{y, \text { stem }}<P_{u, \text { Exp. }} \leq P_{u, \text { stem }} \ldots \ldots \ldots . .(18(\mathrm{~b}))
\end{aligned}
$$

It will be also verified through analytical investigation guided by FE analysis results.

\section{3D FE T-stub Connection Models}

The ABAQUS nonlinear FE code program ${ }^{25)}$ was used to predict the response of bolted T-stub connections. FE connection models consisted of several independent parts as shown in Fig. 7. The FE connection models were made up of 3D solid elements incorporating fully nonlinear material properties, geometric nonlinearity, symmetric boundary conditions, prescribed displacement, and initial bolt pretension. In addition, surface interactions combined with friction and rough condition were assigned between adjacent faying surfaces. They lead to the slip resistance. Especially, friction occurring at the faying surface between the beam flange and the T-stub became the main source of force transfer before the transmitted axial force arrived at the slip load. The FE connection models incorporated nonlinear material behaviors simulated by true stress vs. total true 
strain curves. The connections were modeled as half models using symmetric boundary conditions for the purpose of shortening the analysis time.

The FE connection models were loaded in two steps. The bolt pretension was generated by applying an adjusted length to the bolt shank during the first step, and then propagated to the second step. Prescribed displacements were uniformly adjusted with the value of $0.20 \mathrm{~mm}$ at the middle of tension bolt shanks. On the other hand, according to the FE connection models, different adjusted length was imposed at the shear bolts in order that the slip resistance obtained from the FE analysis is accurately calibrated to that from the experimental test. The tip of the bolt was fully fixed during the first step and then released during the second step. To generate a bending moment at the connection, the main displacement loads were imposed on the tip of the beam corresponding to the position of a loading actuator (see Fig. 1(b)) only during the second step. The reaction forces corresponding to these imposed displacement loads were measured by using the history output instrument in the ABAQUS program.

\section{FE Analysis Results}

Comparisons between experimental test results and FE analysis results, in terms of applied moment vs. total rotation curves, are presented in Fig. 8. Both results comprehensively show good agreements with respect to the initial stiffness, ultimate strength, shape of the envelop, and even level of the slip plateau. All connections models satisfy the design criterion in that they exceed the full plastic strength of the beam $\left(M_{p}\right)$. When each pair of connection models having different bolt diameters (e.g., FS05-TA01 vs. FS06TA09) are compared, it is noted that the diameter of tension bolts has much less influence on the increase of the ultimate strength than other geometric parameters. The deformable contribution of tension bolts may be negligible as compared to that of desirable component yielding because connection models were designed with the relatively higher strength capacity of tension bolts. Accordingly, the bolt fracture does not occur before the connection components yield. This hypothesis can be verified by observing the stress contour distributed over the connection.

Figure 9 shows the distribution of the Mises stress
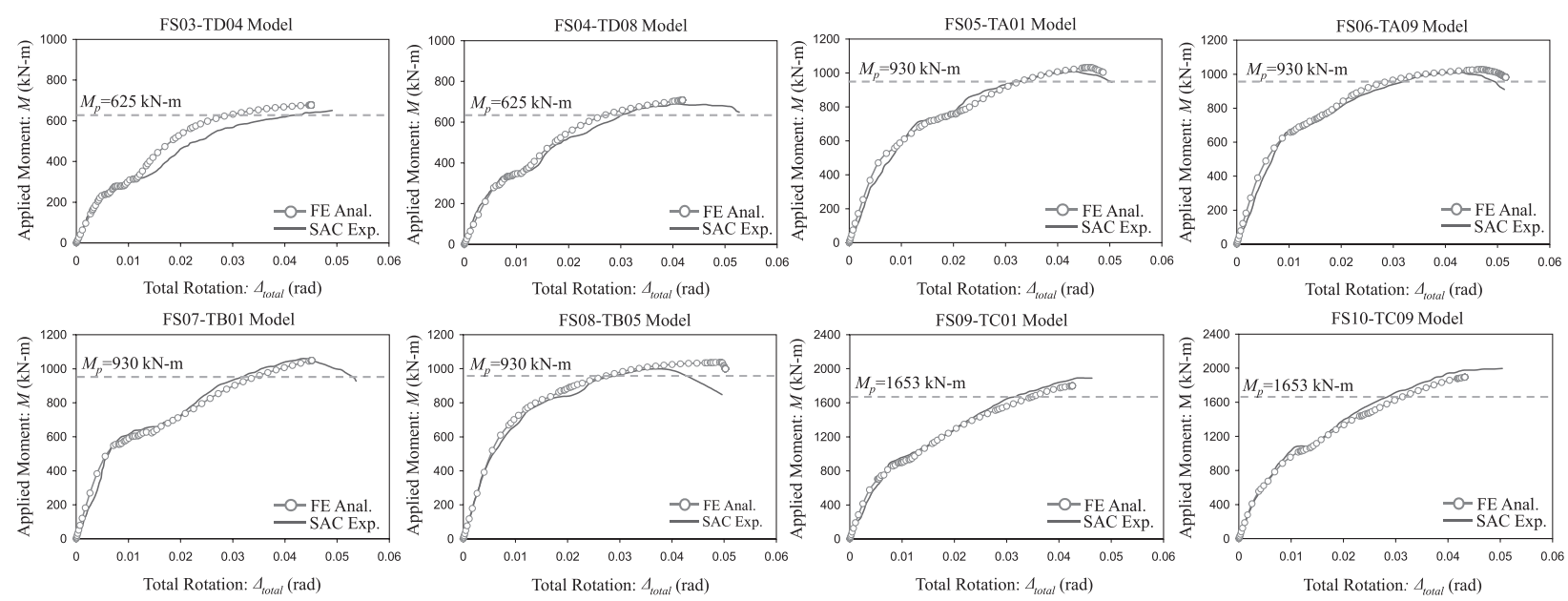

Fig. 8. Comparison of overall moment-rotation response between FE analysis and experimental test.

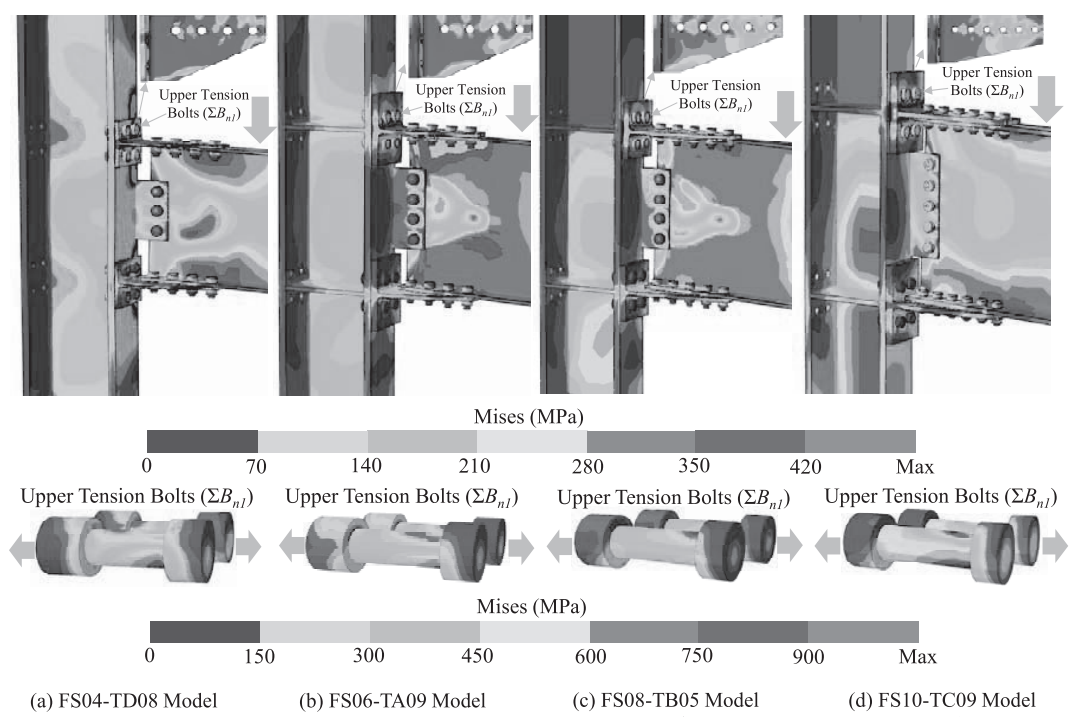

$\begin{gathered}\text { (a) FS04-TD08 Model } \\ \left(M=708 \mathrm{kN}-\mathrm{m}, \Delta_{\text {total }}=0.042 \mathrm{rad}\right)\end{gathered}\left(M=982 \mathrm{kN}-\mathrm{m}, \Delta_{\text {total }}=0.052 \mathrm{rad}\right)\left(M=1001 \mathrm{kN}-\mathrm{m}, \Delta_{\text {total }}=0.050 \mathrm{rad}\right)\left(M=1890 \mathrm{kN}-\mathrm{m}, \Delta_{\text {total }}=0.043 \mathrm{rad}\right)$

Fig. 9. Observation of Mises stress distribution at the final displacement load. 
including the deformed configuration at the final displacement load. The upper T-stub under tension force pulled out the tension bolts while the lower T-stub under bearing compression pulled back the shear bolts into the steel column. For the beam, the plastic yield stress, which was plotted as the red color at the stress contour, concentrated on the flange, and then spread into the web fast. Moreover, the amount of the plastic yield stress was accumulated at the Tstem near the K-zone. The stress contours at the tension bolts highlight the prying force as well as the local bending moment. Due to the bending effect in the tension bolts, the concentration of the plastic yield stress occurs underneath a one-sided bolt head. This bending effect acts to reduce their axial strength capacity. The amount of the prying force can be approximately predicted by examining the intensity of the stress contour on the tip of the upper T-stub flange. The more intense level of the stress contour distributed over the upper T-stub flange was observed at the FS04-TD08 model in comparison with the FS10-TC09 model (see Figs. 9(a) and 9(d)). It can be concluded that the FS04-TD08 model produces more prying forces than the FS10-TC09 due to the smaller flange capacity as presented in Table 3. T-stems and a beam yielded more than tension bolts as also shown in these figures. As a result, the yielding of such components seems to precede the bolt fracture.

\section{Investigations of FE Analysis Results}

Several general observations from FE connection models after analyses are able to provide valuable and qualitative information on the nonlinear behavior of the T-stub components under actual loading conditions. The first aspect to take into consideration is to investigate the overall forcedeformation response of T-stub components. Three selected resulting curves, which were measured from LVDTs F (see Fig. 3), are shown in Fig. 10. The applied axial forces were converted in accordance with the first order approximation defined as Eq. (5). The limits for the plastic yielding of the
T-stem $\left(P_{y, \text { stem }}\right)$ are also plotted in the figures. Except for the FS08-TB05 model, the ultimate capacities obtained from experimental and analytical results exceed these limits. The slightly larger over-strength was achieved owing to the hardening range found between the yield stress $\left(F_{y}\right)$ and the ultimate tensile stress $\left(F_{u}\right)$ of the base T-stem material. The main plastic deformation of the T-stub component occurs at the state adjacent to the yielding of the T-stem. Thus, the Tstem contributes to increasing energy capacity and ductility in the connection behavior.

In addition to the deformable contribution, the response mechanism for other component members can be also investigated through FE analysis results. Figure 11 shows the capacity of the T-stub flange plotted as the function of the flange thickness. Two T-stubs, TB05 and TC01, are selected to investigate the capacity of the T-stub flange according to the geometric parameters concerning the T-stub flange thickness $\left(t_{f}\right)$, the ratio of $H_{1}$ to $H_{2}$, and the diameter of the bolt $\left(d_{b}\right)$. The failure modes are also involved with these geometric parameters. The line section $\mathrm{OC}, \mathrm{CD}$, and $\mathrm{DE}$ are calculated by means of Eqs. (7), (8), and (9), respectively. On the other hand, the line section OB is computed in accordance with the equation resulting from Eq. (11). The point $\mathrm{B}$ represents the ultimate strength of the T-stub flange corresponding to the T-stub flange thickness.

For the FS08-TB05 model with $t_{f}=240 \mathrm{~mm}, H_{1} / H_{2}=0.48$, and $d_{b}=25 \mathrm{~mm}$, the line section $\mathrm{OB}$ is drawn with $\alpha=1.63$ (see Table 3). The line section ABC indicates a bolt fracture in tension after the plastic hinge has been developed in the T-stub flange. The ultimate strength capacity of the T-stub flange (i.e., $P_{n \text {,flange }}=2800 \mathrm{kN}$ ) is obtained from the Point $\mathrm{B}$ anchored to the extended line section ABC. After establishing the plastic hinge mechanism, the T-stub flange can resist additional forces until tension bolts fail by the fracture. It is because that strain hardening was applied to the base material of the T-stub flange. Thus, owing to the value of $\alpha$ exceeding 1.0, the plastic hinge mechanism occurring at the line section $\mathrm{OC}$ results in the theoretical failure mode
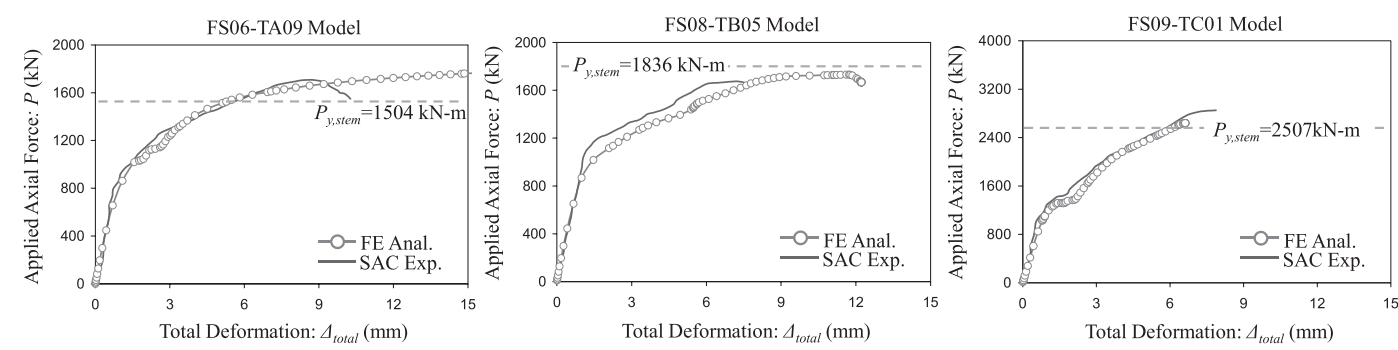

Fig. 10. Overall force-deformation response of T-stub components.
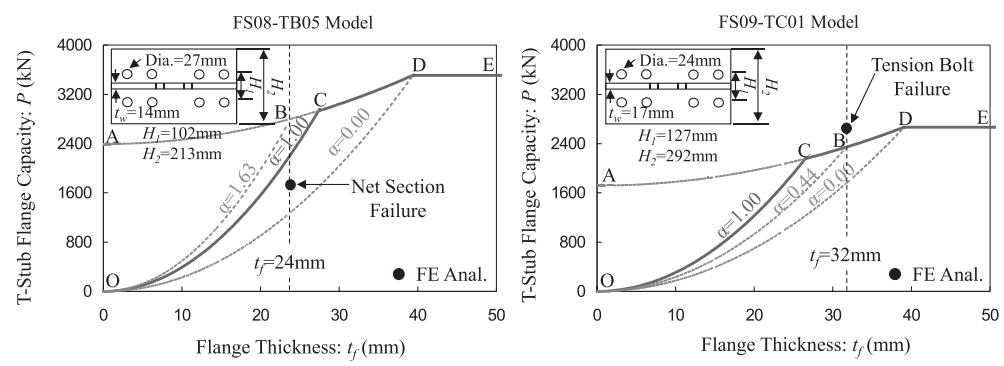

Fig. 11. Determination of the strength capacity at the T-stub flange based on the solution space. 


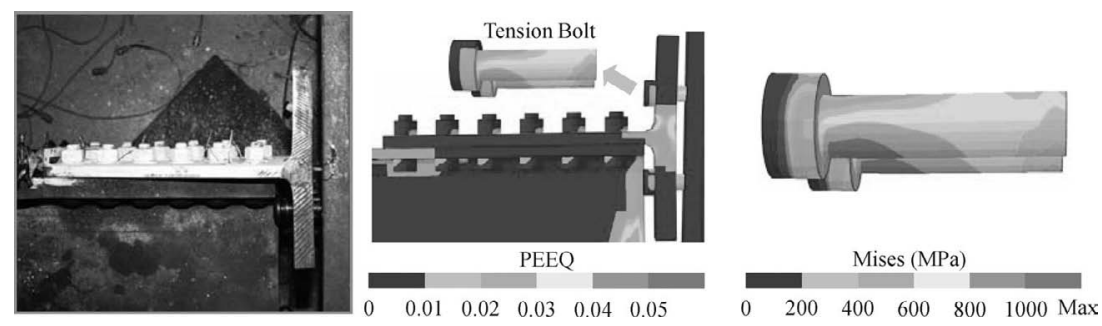

Fig. 12. Investigation of the failure mode on connection components with FE analysis results (FS09-TC01 model).

but does not represent the ultimate strength capacity. For the FS09-TC01 model with $t_{f}=32 \mathrm{~mm}, H_{1} / H_{2}=0.43$, and $d_{b}=$ $22 \mathrm{~mm}$, the line section OB is drawn with $\alpha=0.44$. As a result, the Point $\mathrm{B}$ referred to as the ultimate strength capacity of the T-stub flange (i.e., $P_{n \text {,flange }}=2344 \mathrm{kN}$ ) is anchored to the line section $\mathrm{CD}$.

The ultimate capacity of the T-stub component obtained from the FE analysis $\left(P_{u, \text { Anal. }}\right)$ is also plotted as the solid symbol on the solution space in an effort to verify the sequence of failure modes. The ultimate T-stub capacity of the FS08-TB05 model should lie below the capacity curve for the T-stub flange $\left(P_{n, \text { flange }}>P_{u \text {,Anal. }}=1680 \mathrm{kN}\right)$ on the ground that this connection model failed by the net section fracture preceding the failure of the T-stub flange, as presented in Eq. (18(a)). The bolt fracture also provides insight. For the FS09-TC01 model, the ultimate T-stub capacity lies just above the capacity curve $\left(P_{n, \text { flange }}>P_{u, \text { Anal. }}=2650 \mathrm{kN}\right)$. This model fails by the tension bolt fracture that follows the failure of the T-stub flange, as presented in Eq. (18(b)). The ultimate T-stub capacity reaches the tensile capacity of bolts very close $\left(\Sigma B_{n, \text { tension }}=2665 \mathrm{kN}\right)$.

The observation of field output contours is also needed to investigate not only the dominant failure mode but also the bolt prying mechanism. The Von-Mises stress (Mises) and equivalent plastic strain (PEEQ) field output contours, which were distributed to the tension bolt and the T-stub under the ultimate load, are shown in Fig. 12. The FS09TC01 model is selected for investigation. The intensity of the plastic strain contour demonstrates that bolt shanks underneath the one-sided bolt head undergo plastic deformations on account of the axial force combined with the local bending moment. Particularly, the plastic hinge determined in conformity with the intensity of approximately 4.0 percent plastic strain is found at the section of the K-zone. This physical phenomenon observed can prove the sequence of failure modes for the FS09-TC01 model as discussed above. Likewise, the final deformed configuration obtained from the experiment fits well into that from the FE analysis in respect that the T-stub flange is completely separated from the column flange. According to the final deformed shape of component members, the ultimate failure for this model can be characterized by the Failure Mode Case $\mathrm{C}$ presented in Fig. 5(c). Therefore, the prying force becomes zero at the ultimate loading state.

Bolt reaction forces $\left(B_{n}\right)$ measured from FE models after analyses are also utilized to examine the prying response of the FS09-TC01 model beyond the experimental test results. The detail investigation into the prying response of tension bolts is presented in Fig. 13. The blue solid line represents the behavior of the connection where no bolt prying and

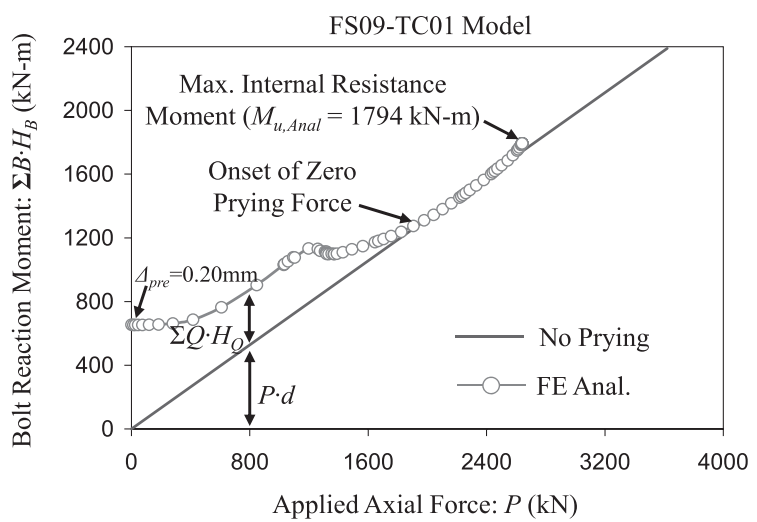

Fig. 13. Prying action response of tension bolts.

zero initial bolt pretension are taken into account. However, most of the connection behavior obeys the path of curves reproduced by the FE analyses. The bolt reaction forces are converted into the internal reaction moments defined in Eq. (3) (see also Fig. 4). The summation of internal reaction moments starts at a non-zero point because tension bolts are initially pretensioned. For this reason, the prying force corresponds to the bolt reaction force at the beginning of the loading state. As the converted axial force $(P)$ increases, the internal reaction moment in the tension bolts also increases. Note that the solid arrows displayed above $P=800 \mathrm{kN}$ in Fig. 13 are employed to emphasize the static equilibrium derived from Eqs. (3) and (6), such that $M_{r}=\Sigma B_{n} H_{B}=$ $P d+\Sigma Q H_{Q}$. When the loading state proceeds to approximately $P=2000 \mathrm{kN}$, the prying force converges to zero, and then separation starts to occur between T-stub flange and column surface. Thenceforth, the zero prying force continues until the ultimate load $\left(P_{u, \text { Anal. }}=2650 \mathrm{kN}\right.$ and $M_{u, \text { Anal. }}=$ $1794 \mathrm{kN}-\mathrm{m}$ ), and then the converted axial force is directly transmitted into the tension bolt. The bolt fracture is easy to arise for this reason.

Other behavioral characteristics such as slip plateau and bolt bearing deformations can be also elucidated through FE analyses. Figure 14 shows the slip response measured in the experiments with LVDTs B (see Fig. 3) and the corresponding FE analysis results. The coefficient of friction and the initial pretension of shear bolts result in the critical parameters to determine the load at the initial slip. The elastic deformation is observed at the curve before slippage occurs. The friction coefficient was uniformly applied to shear faying surfaces between the beam flange and the T-stub with the value of 0.5 . Due to the variable displacement used for the initial shear bolt pretension, FE analyses provide the best match into the experimental test data where the level of the slip plateau referred to as the slip resistance was various (see 

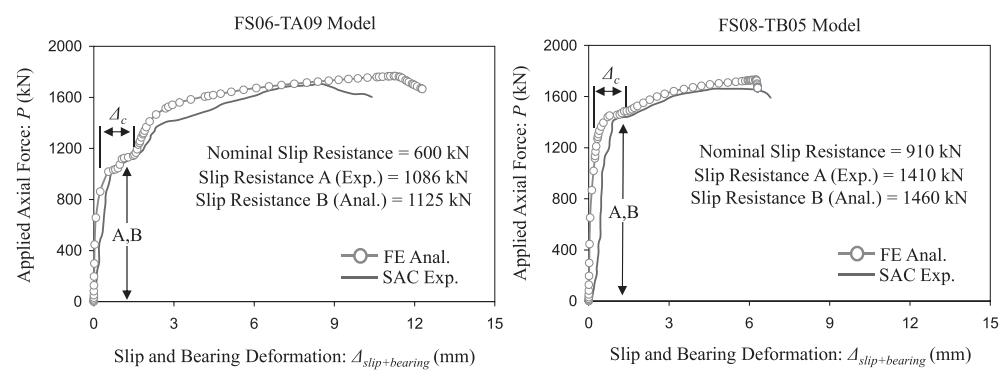

Fig. 14. Force-slip and bearing deformation response of $\mathrm{T}$-stub components.
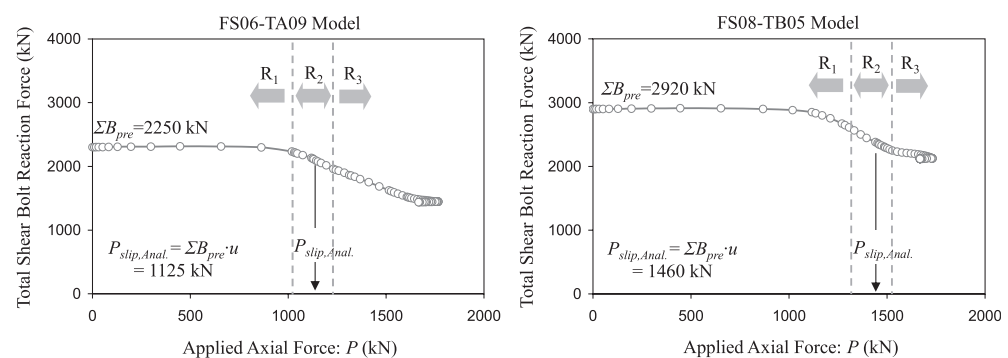

Fig. 15. Slip response of shear bolts.

A and B in Fig. 14). One would expect very consistent results in this characteristic from the FE models since the uniform clearance between bolt shanks and around bolt holes $\left(\Delta_{c}=1.6 \mathrm{~mm}\right)$ were made in all FE analyses. Sliding continues to occur until the shanks of shear bolts come into contact with the inner surface of bolt holes. The shear bolts come into bearing thereafter. Bearing deformations start to increase the slope of the loading curves again. The FS06TA09 model shows a clear slip plateau and bearing deformation, while the FS08-TB05 model has a combination of slip and yielding around $1460 \mathrm{kN}$. Overall, FE analysis results show satisfactory agreement with the experimental results.

Additional observations for the shear bolt reaction forces that have influence on the slip response are illustrated in Fig. 15. The variable adjustment length of shear bolts causes to generate different initial bolt pretension forces according to the connection models (e.g., $\Sigma B_{\text {pre }}=2250 \mathrm{kN}$ and $\Sigma B_{\text {pre }}=$ $2920 \mathrm{kN}$ for the FS06-TA09 model and the FS08-TB05 model, respectively). The path of the curve shown in the figures can be divided into three stages defined as the dashed lines so as to evidently explain the procedure of the slip behavior. The reaction force preserves the initial bolt pretension prior to slippage $\left(R_{1}\right.$ in Fig. 15). During the section of the slip $\left(R_{2}\right)$, the reaction force is on the decrease due to the loss of the bolt pretension. The applied axial force continuously increasing exceeds the slip resistance which results in the product of the initial bolt pretension and the friction coefficient $\left(P>P_{\text {slip }}=\Sigma B_{\text {pre }} \cdot u\right)$. The bolt reaction force is continuously decreasing during the bearing deformation $\left(\mathrm{R}_{3}\right)$. Finally, it starts to maintain the constant level again at the onset of yielding around shear bolt holes.

\section{Concluding Remarks}

The refined 3D FE models successfully predicted the complete behavior of full-scale connections. The local behavior of T-stub component members was also captured well by the FE models, which accurately reproduce the development of a prying mechanism, the sequence of sliding, and bearing contact. Moreover, FE analysis results, which were found to be in good agreement with the actual connection behavior, are used to review behavioral changes as the consequence of geometric variations.

The prying action mechanism tends to be more influenced by flange thickness and tension bolt location. The amount of the prying force according to these geometric variations can be clearly identified by observing stress distributions and bolt force tracks. In addition, computations on the strength capacity for the T-stub flange were made, presenting the T-stub failure modes found at FE connection models after analyses, and emphasizing the interaction between the T-stub flange and the tension bolts. Except for the FS09TC01 model, the tension bolts were not sufficient to develop the plastic deformation in the connection.

The slip model, which determines the slip resistance, is sensitive to bolt pretension as well as a friction coefficient. In the same manner of the experimental test, the value of the adjusted length for generating initial bolt pretension in the FE model remains a random variable. However, the uniform friction coefficient to define the surface interaction between T-stem and beam flange was applied to all FE models. Consequently, the level of the slip plateau evaluated from the FE analysis fits into that obtained from the corresponding experimental test very well.

Based on the failure mode, ideal T-stub connection design is one where the ultimate strength is governed by the yielding to the T-stem. The yielding of the T-stem is followed by the ultimate strength of the T-stub flange and finally followed by that of the tension bolts. This failure sequence offers a balanced failure which utilizes the deformation capacity of both stem and flange to the maximum. Especially, the T-stem member was allowed not only to behave in ductile manner but also to achieve substantial deformation. FE analysis results are useful to quantify ideal design because they were found to be in good agreement with the 
order of strength capacities for the balanced failure.

Finally, it is concluded that FE models proposed herein can be considered as reliable tool to reproduce the complex connection behavior and to estimate the response mechanism according to the parametric effect. They also provide valuable data to assess failure modes and strength capacities.

\section{Acknowledgements}

This work was sponsored by the Sustainable Building Research Center of Hanyang University, which was supported by the SRC/ERC program of the Ministry of Education \& Science Technology (MEST) (Grant No. R11-2005-05601003-0). The first author would like to sincerely thank the National Science Foundation (NSF) for six years of financial support (US Grant No. 0324542) as a research assistantship and a post-doctorate fellowship at Georgia Tech.

\section{REFERENCES}

1) T. Kim and B. Han: ISIJ Int., 47 (2007), No. 6, 920.

2) T. Kim, H. Kuwamura, T. Cho, S. Shin, S. Kim and Y. Lee: ISIJ Int., 48 (2008), No. 6, 851.

3) R. T. Leon: Eng. Struct., 20 (1988), 364.

4) J. Hu and R. T. Leon: Proc. of 3rd Int. Symp. On Steel Structure, ISSS, Korea, (2005).

5) J. Hu, Y. Kang, D. Choi and T. Park: IJOSS, KSSC, 10 (2010), No. 2,177 .
6) J. Yang and S. Jeon: IJOSS, KSSC, 9 (2009), No. 3, 195.

7) J. A. Swanson and R. T. Leon: J. Struct. Eng., ASCE, 126 (2000), No. 1,50 .

8) J. A. Swanson and R. T. Leon: J. Struct. Eng., ASCE, 127 (2001), No. $5,498$.

9) S. Ju, C. Fan and G. Wu: Eng. Struct., 26 (2004), 403.

10) R. T. Leon: FEMA 288 (SAC Rep. 95-09), SAC Joint Venture, Sacramento, CA, USA, (1997).

11) A. Azizinamini and S. P. Schneider: J. Struct. Eng., ASCE, 130 (2004), No. 2, 213.

12) G. A. Rassati, R.T. Leon and S. Noe: J. Struct. Eng., ASCE, 130 (2004), No. 2, 343.

13) C. J. Gantes and M. E. Lemonis: Comput. Struct., 81 (2003), 595.

14) Z. Al-Khatab and A. Bouchair: J. Constr. Steel Res., 63 (2007), 1603.

15) M. E. Lemonis and C. J. Gantes: J. Constr. Steel Res., 65 (2009), 879.

16) V. Piluso and G. Rizzano: J. Constr. Steel Res., 64 (2008), 655.

17) J. Smallridge: M. S. Thesis, Georgia Institute of Technology, (1999).

18) C. Schrauben: M. S. Thesis, Georgia Institute of Technology, (1999).

19) American Institute of Steel Construction (AISC): Manual of Steel Construction, Load and Resistance Factor Design (LRFD), 3rd ed., Chicago, IL, (2001).

20) J. Hu: Ph.D. Dissertation, Georgia Institute of Technology, (2008).

21) G. L. Kulak, J. W. Fisher and J. H. A. Struik: Guide to Design Criteria for Bolted and Riveted Joint, 2nd ed., Johns Wiley \& Sons, (1987).

22) W. A. Thornton: J. Eng., AISC, 22 (1985), No. 2, 67.

23) R. E. Whitemore: Experimental Investigation of Stresses in Gusset Plate, University of Tennessee Engineering Experiment Station, Bulletin, (1952), No.16.

24) American Institute of Steel Construction (AISC): Seismic Provisions for Structural Steel Buildings (ANSI/AISC 341-05), Chicago, IL, (2005).

25) ABAQUS: Standard User's Manual. Habbit, Karlsson and Sorenson, Inc., (2008). 